\title{
Patient-derived xenografts as compatible models for precision oncology
}

Sung-Yup Cho ${ }^{1,2,3}$

\begin{abstract}
Cancer is a very heterogeneous disease, displaying heterogeneity between patients (inter-tumoral heterogeneity) and heterogeneity within a patient (intra-tumoral heterogeneity). Precision oncology is a diagnostic and therapeutic approach for cancers based on the stratification of patients using genomic and molecular profiling of tumors. To develop diagnostic and therapeutic tools for the application of precision oncology, appropriate preclinical mouse models that reflect tumor heterogeneity are required. Patient-derived xenograft (PDX) models are generated by the engraftment of patient tumors into immunodeficient mice that retain several aspects of the patient's tumor characteristics, including inter-tumoral heterogeneity and intra-tumoral heterogeneity. Therefore, PDX models can be applied in various developmental steps of cancer diagnostics and therapeutics, such as biomarker development, companion diagnostics, drug efficacy testing, overcoming drug resistance, and co-clinical trials. This review summarizes the diverse aspects of PDX models, addressing the factors considered for PDX generation, application of PDX models for cancer research, and future directions of PDX models.
\end{abstract}

Keywords: Patient-derived xenograft, Precision oncology, Cancer preclinical model, Tumor heterogeneity, Targeted therapeutics, Drug efficacy test

\section{Introduction}

Cancer is a heterogeneous disease caused by the combination of genomic, epigenomic, and transcriptomic alterations in cells. Recent studies using high-throughput parallel sequencing technology have demonstrated that even tumors from the same organ possess varying combinations of such alterations [1-3]. Therefore, to understand the natural cancer biology and provide appropriate interventions, precise stratification of cancers is required. Precision oncology is a strategic approach for cancer treatment, which uses molecular profiling of cancers for stratification of patients [4]. The strategy of precision oncology is closely associated with the development of

Correspondence: csybio@snu.ac.kr

${ }^{1}$ Department of Biomedical Sciences, Seoul National University College of Medicine, 103 Daehak-ro, Jongno-gu, Seoul 03080, South Korea

${ }^{2}$ Cancer Research Institute, Seoul National University College of Medicine, Seoul, South Korea

Full list of author information is available at the end of the article biomarkers for cancer stratification and targeted therapeutics for the classified subgroups.

One of the hurdles for the development of biomarkers and targeted therapeutics is the availability of suitable preclinical animal models. Popularly used mouse models, including cell line-derived xenograft models and genetically engineered mouse (GEM) models, display only limited genetic diversity compared with the heterogeneous characteristics of human cancers [5]. Ideal animal models for cancer research should maintain the diversity of patient characteristics and allow for easy performance of model generation. Patient-derived xenograft (PDX) models are generated by transplanting the patient's intact tumor tissue into immunodeficient mice, resulting in the growth of human cancers in the background of a mouse host [6]. As a result, a considerable degree of the patient's tumor characteristics can be preserved, including histological and genomic features [7]. Therefore, of all the preclinical cancer models developed to date, PDX

C C The Author(s). 2020 Open Access This article is licensed under a Creative Commons Attribution 4.0 International License, which permits use, sharing, adaptation, distribution and reproduction in any medium or format, as long as you give appropriate credit to the original author(s) and the source, provide a link to the Creative Commons licence, and indicate if changes were made. The images or other third party material in this article are included in the article's Creative Commons licence, unless indicated otherwise in a credit line to the material. If material is not included in the article's Creative Commons licence and your intended use is not permitted by statutory regulation or exceeds the permitted use, you will need to obtain permission directly from the copyright holder. To view a copy of this licence, visit http://creativecommons.org/licenses/by/4.0/ The Creative Commons Public Domain Dedication waiver (http://creativecommons.org/publicdomain/zero/1.0/) applies to the data made available in this article, unless otherwise stated in a credit line to the data. 
models most closely reflect patients' tumor characteristics and, accordingly, patients' responsiveness to treatment $[7,8]$. Therefore, PDX models can apply to diverse fields of cancer research.

To apply PDXs models to several areas of cancer research, their characteristics and limitations need to be evaluated. In this review, we summarize several aspects of PDX models, including factors related to model generation, application to diverse cancer research fields, and approaches to overcome limitations.

\section{Factors related to the generation of PDX models General procedure for PDX generation}

PDX models can be generated by engrafting patient tumor tissues into immunodeficient mice (Fig. 1). Tumor tissues are usually obtained from surgical specimens, but those obtained by biopsy can also be applied to generate models [9]. In the operation room, the obtained tumor tissues are washed and stored in cell culture media with antibiotics. To reduce tissue metabolism, they should be maintained at low temperature. Additionally, to reduce ischemia, the tumor tissues should be transferred to an animal facility as soon as possible. A prolonged ischemia time is known to be associated with a lower engraftment rate [10]. Tumor tissues are prepared by removing dead and necrotic areas and are then cut into sizes of $2-3 \mathrm{~mm}^{3}$. The mice are first prepared by anesthetization and sterilization of the implanting area. The tumor pieces are surgically implanted, usually in subcutaneous tissue. The compatible organs for the tumor origin can be considered for orthotopic implant models. After surgery, the mice are recovered from anesthesia by maintaining the body temperature using a warm pad or infrared lamp. Tumor growth is evaluated regularly, and when the tumor size reaches approximately $1000 \mathrm{~mm}^{3}$, the tumors are harvested and stored for the next passage. It usually takes about 3-6 months for tumor harvest, but it depends on the individual tumor characteristics [6]. The harvested tumors are prepared by removing necrotic areas and cutting into appropriate sizes for preservation. The PDX tumor tissues are stored in a liquid nitrogen tank by cryopreservation and can be re-implanted into new mice for the next passage. The generated PDX tumors are evaluated by histological and genomic analyses to ensure conservation of the patient's tumor characteristics.

\section{Tumor characteristics}

The engraftment success rate of PDX models varies with the type of cohort reported and generally depends on the tissue types of tumor origin. Previous reports have demonstrated that colon cancers (76-89\%) [11, 12], pancreatic cancers $(45-62 \%)[13,14]$, non-small cell lung cancers $(41-90 \%)[15,16]$, biliary tract cancers $(54 \%)$ [17], head and neck cancers (85\%) [18], and medulloblastoma (52\%) [19] have high success rates of PDX generation. However, breast cancers (13-21\%) [20, 21], gastric cancers (24\%) [22], liver cancers (14\%) [23], kidney cancers (37\%) [24], bladder cancers (15\%) [25], and melanoma (28\%) [26] have low success rates (Table 1). The tumor histological types were reportedly associated with the success rate of PDX generation in some types of cancers, such as lung and gastric cancers (Table 1) $[15,22]$. In the case of estrogen receptor-positive breast cancer with low malignancy, the success rate tends to be low; if necessary, the supplementation of human estrogen pellets would be required for model production [27]. Despite same tissue origin, tumors with clinically high malignancy or metastatic properties tend to exhibit a relatively high success rate $[19,28,29]$. In some reports, the success of PDX was associated with tumor aggressiveness, and patients whose tumors were successfully engrafted in the PDX models showed a poorer prognosis

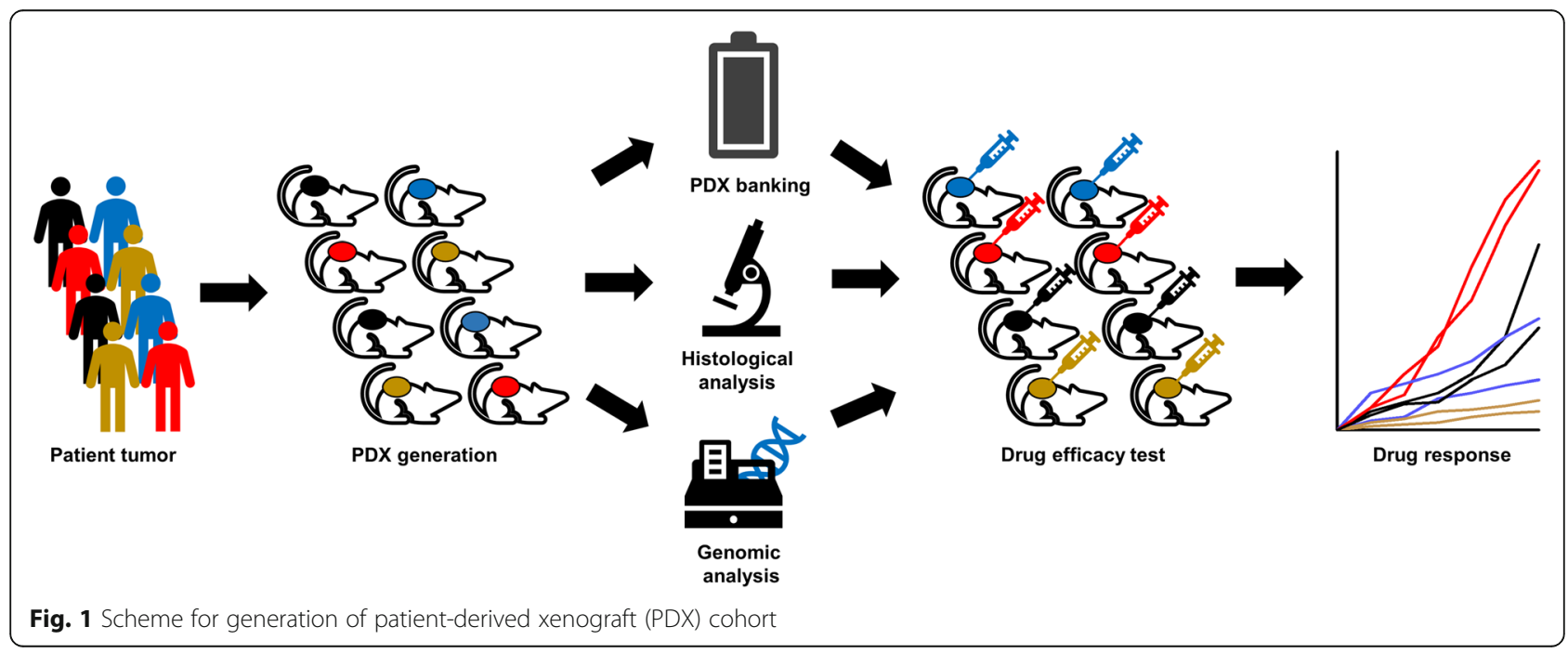


Table 1 Summary of engraftment rates of PDX tumors

\begin{tabular}{|c|c|c|c|c|c|}
\hline Tumor type & Mice strain & Implantation site & Engraftment rate & $\begin{array}{l}\text { Engraftment-related } \\
\text { factors }\end{array}$ & References \\
\hline \multirow[t]{2}{*}{ Colorectal cancer } & NSG & Subcutaneous & $76 \%$ & & Cho et al., 2019 [11] \\
\hline & Nude & Orthotopic & $89 \%$ & & Aytes et al., 2012 [12] \\
\hline \multirow[t]{2}{*}{$\begin{array}{l}\text { Pancreatic cancer } \\
\text { (ductal adenocarcinoma) }\end{array}$} & Nude & Subcutaneous & $45 \%$ & $\begin{array}{l}\text { Post-operation } \\
\text { CA 19-9 level }\end{array}$ & Chen et al., 2020 [13] \\
\hline & ICR SCID & Subcutaneous & $67 \%$ & & Mattie et al., 2013 [14] \\
\hline \multirow[t]{2}{*}{ Breast cancer } & SCID/Beige, NSG & Mammary fat pad & $19-21 \%$ & & Zhang et al., 2013 [20] \\
\hline & NOD/SCID & Humanized mammary fat pad & $13 \%$ & & Li et al., 2013 [21] \\
\hline \multirow[t]{2}{*}{ Non-small cell lung cancer } & Nude, NOG & Subcutaneous & $41 \%$ & $\begin{array}{l}\text { Brain metastasis, SCC } \\
\text { histology, tumor stage, } \\
\text { wild-type EGFR }\end{array}$ & Lee et al., 2015 [15] \\
\hline & $\mathrm{NOD} / \mathrm{SCID}$ & Renal capsule & $90 \%$ & & Dong et al., 2010 [16] \\
\hline Gastric cancer & NOG & Subcutaneous & $24 \%$ & $\begin{array}{l}\text { Intestinal type, high } \\
\text { tumor cell percentage, } \\
\text { short procedure time }\end{array}$ & Choi et al., 2016 [22] \\
\hline $\begin{array}{l}\text { Liver cancer } \\
\text { (hepatocellular carcinoma) }\end{array}$ & NSG & Subcutaneous, orthotopic & $14 \%$ & & Zhu et al., 2020 [23] \\
\hline $\begin{array}{l}\text { Kidney cancer } \\
\text { (renal cell carcinoma) }\end{array}$ & $\mathrm{NOD} / \mathrm{SCID}$ & Orthotopic (Renal capsule) & $37 \%$ & $\begin{array}{l}\text { Tumor stage, Tumor } \\
\text { implanted from } \\
\text { metastatic site }\end{array}$ & Sivanand et al., 2012 [24] \\
\hline $\begin{array}{l}\text { Bladder cancer } \\
\text { (urothelial carcinoma) }\end{array}$ & BALB/ c-nu & Subcutaneous & $15 \%$ & & Park et al., 2013 [25] \\
\hline $\begin{array}{l}\text { Biliary tract cancer } \\
\text { (cholangiocarcinoma and } \\
\text { gallbladder cancers) }\end{array}$ & $\mathrm{NOD} / \mathrm{SCID}$ & Subcutaneous & $54 \%$ & $\begin{array}{l}\text { Surgical resection, } \\
\text { median ischemic time }\end{array}$ & Leiting, 2020 [17] \\
\hline $\begin{array}{l}\text { Head and neck cancer } \\
\text { (squamous cell carcinoma) }\end{array}$ & NSG & Subcutaneous & $85 \%$ & Lymph node positive & Kimple et al., 2013 [18] \\
\hline Medulloblastoma & Rag2 SCID & Orthotopic & $52 \%$ & & Zhao et al., 2012 [19] \\
\hline Uveal melanoma & NOD/SCID & Subcutaneous & $28 \%$ & Metastasis & Némati et al., 2010 [26] \\
\hline
\end{tabular}

than those without success in PDX generation [30, 31]. Therefore, the success rate of the PDX models is largely affected by tumor origin and aggressiveness.

\section{Mouse strains}

Several types of immunodeficient mice have been used to generate PDX models. Representative mouse types include nude mice, scid (severe combined immunodeficient) mice, non-obese diabetic (NOD)/scid mice, and NSG (NOD/scid/interleukin [IL] $2 \gamma$-receptor null) mice [6]. Because each mouse has different immunological characteristics and different degrees of immunosuppression in immune cell functions, it is important to understand the characteristics of each mouse strain and use compatible mice suited to the study purpose. Nude mice do not develop $\mathrm{T}$ cells because thymus development is inhibited by mutations in the Foxn1 gene [32]. Scid mice lack $\mathrm{T}$ cells and $\mathrm{B}$ cells due to mutations in the Prkdc gene, which is involved in DNA double-strand break repair [33]. NOD/scid mice lack the functions of T cells, B cells, and natural killer (NK) cells [34]. NSG mice have an additional deletion of IL2 $\gamma$ receptors compared with
$\mathrm{NOD} /$ scid mice. Therefore, these mice not only lack $\mathrm{T}$ cells, B cells, and NK cells just like NOD/scid mice, but also lack the function of immune cells related to innate immunity, such as macrophages and dendritic cells, resulting in the most severe immunosuppression among immunodeficient mice [35]. The success rate of PDX was reported to be lower in nude mice than in other types of mice because of the lower degree of immunosuppression, but no significant difference was reported in the success rates among the other types of mice [6]. The higher the degree of immunosuppression, the more likely the success rate of the PDX model; however, problems may arise due to the activation of human-derived viruses such as Epstein-Barr virus (EBV). Severe immunosuppressive mice such as NOD/scid and NSG mice have been reported to develop human cell-derived lymphoma caused by EBV activation of human cell origin $[11,36]$.

\section{Transplantation sites}

The most commonly used transplantation site for the generation of PDX models is the flank of the mouse (subcutaneous model; Table 2). The advantage of 
Table $\mathbf{2}$ Comparison of several types of patient-derived xenograft models

\begin{tabular}{|c|c|c|}
\hline PDX model & Advantage & Challenges \\
\hline Subcutaneous model & $\begin{array}{l}\text { - Easy procedure } \\
\text { - Minimized tissue damage of mice } \\
\text { - Easy evaluation of tumor growth } \\
\text { - Maintaining tumor architecture and clonality }\end{array}$ & $\begin{array}{l}\text { - Lack of proper tumor microenvironment } \\
\text { - Lack of metastasis }\end{array}$ \\
\hline Orthotopic model & $\begin{array}{l}\text { - Preservation of microenvironment of primary } \\
\text { tumor } \\
\text { - Spontaneous metastasis }\end{array}$ & $\begin{array}{l}\text { - Requirement of microsurgical skills } \\
\text { - Imaging equipment required for } \\
\text { longitudinal study }\end{array}$ \\
\hline Subrenal model & - Increased blood supply for tumor growth & $\begin{array}{l}\text { - Requirement of microsurgical skills } \\
\text { - Imaging equipment required for } \\
\text { longitudinal study }\end{array}$ \\
\hline Humanized model & $\begin{array}{l}\text { - Reconstitution of human immune cells } \\
\text { - Evaluation of cancer immunotherapy }\end{array}$ & $\begin{array}{l}\text { - Requirement of long time for } \\
\text { humanization and PDX generation } \\
\text { - Limited reconstitution of human } \\
\text { immune system }\end{array}$ \\
\hline Stromal cell co-implantation model & - Supply of human stromal cells in tumor microenvironment & $\begin{array}{l}\text { - Change of tumor characteristics by } \\
\text { stomal cells }\end{array}$ \\
\hline Circulating tumor cell (CTC)-derived model & $\begin{array}{l}\text { - Minimally invasive in patient } \\
\text { - Easy to obtain samples } \\
\text { - Applicable for otherwise unavailable tumor } \\
\text { specimens } \\
\text { - Preservation of intra-tumoral heterogeneity }\end{array}$ & $\begin{array}{l}\text { - Requirement of technique for the } \\
\text { enrichment of CTCs } \\
\text { - Variable concentration of CTCs in blood }\end{array}$ \\
\hline
\end{tabular}

subcutaneous models is that the surgery required to generate the PDX model is very simple and tissue damage can be minimized. Thus, the mouse can easily recover after surgery. Additionally, because tumor growth can be directly evaluated through the skin, it is easy to confirm growth and measure the tumor volume change over time. However, the tumor characteristics become different from those of the primary tumor because the tumor grows in an environment different from that of the original organs [37, 38]. Additionally, subcutaneous models usually do not recapitulate the metastatic processes [37, 38]. Therefore, subcutaneous models can be considered first when constructing a large PDX cohort in a short time. The orthotopic model, in which tumors are transplanted according to the primary tumor site, attempted to overcome the limitations of the subcutaneous model (Table 2). Orthotopic models are produced by surgical transplantation of tumors in the same area as that of the primary tumor-derived organs. The most accessible orthotopic models are those for breast cancer because the mammary gland, the tissue from which breast cancer originates, is easily accessible from the outside and can be transplanted without major surgical procedures [39]. Orthotopic models can preserve the microenvironment characteristics of primary cancers because they are implanted in the organs of primary tumors and are more suitable for metastasis studies [37, 38]. However, skillful surgical techniques are required for successful implantation of tumor tissue. Additionally, because tumor growth is not usually detected from the outside, there is a limitation that monitoring tumor growth requires imaging such as ultrasound or computed tomography. The other option for tumor implantation is a subrenal capsule, which has the advantage of high blood vessel density, resulting in easy formation of blood vessels in tumor tissues (Table 2) [40]. This approach has been tried in several types of cancers, including prostate and ovarian cancers $[41,42]$. Therefore, it is important to select a tumor transplantation site with the appropriate characteristics, according to the purpose of research.

\section{Application of PDX models for cancer research Cancer biology studies}

A big advantage of the PDX models is that they retain much of the characteristics of the patients' tumors [7, 8]. Therefore, various studies that are difficult to perform in patients can be achieved using PDX models. In cancer patients, invasive methods such as biopsies, which involve obtaining tumor tissues, are very limited in application. However, in PDX models, it is easy to acquire tumor tissue after various experimental treatments. Thus, PDX models can be applied to study diverse characteristics of tumor biology such as cancer growth, death, evolution, and metastasis.

PDX models retain the characteristics of the genomic mutations in patient tumors [11], so they can be applied to study the functions of cancer-related gene mutations. Comparing the characteristics of patient groups with or without a specific gene mutation can help assess the effect of that mutation on tumor biology. Analyses of tumor biological changes caused by gene mutations enable precision cancer medicine through the stratification of cancer patients according to their genome profile and the development of targeted treatment strategies [4]. 
Another area of research where PDX models are applicable is tumor heterogeneity. Tumors with the same pathology and originating from the same organs show inter-tumoral heterogeneity, manifesting as different histological, genetic, and malignant characteristics between patients, including morphology, gene expression, proliferation, invasion, and metastasis [43]. Additionally, tumors from the same patient demonstrate the characteristics of intra-tumoral heterogeneity, where histological, genetic, and malignant characteristics evolve according to chronological and regional changes in the tumor [44]. PDX cohorts generated from patient cohorts can be applied as a model to maintain inter-tumoral heterogeneity in patients [45]. Because the tissue from the patient is directly transplanted into the mouse in PDX models, various constituent cells existing in the tumor tissue can be transplanted together [11]. It is also possible to reflect changes in the genome due to cancer evolution, which can cause a considerable amount of heterogeneity in the tumor [11, 45]. Additionally, although a limitation of the mouse tumor microenvironment exists, PDX models recapitulate the pattern of in vivo cancer evolution; therefore, changes in the characteristics of cancer can be analyzed according to passage progression [45]. Thus, the PDX model can be used as an important tool to study cancer heterogeneity and evolution.

\section{Biomarker development}

To precisely diagnose and treat cancer patients, various biomarkers are required to evaluate the patient's condition, and PDX models can be used as a tool to develop biomarkers for clinical application [39, 46]. PDX models make it easier to apply various experimental methods for tumor tissue analysis because patient tumor tissues can be additionally obtained through transplantation and expansion in mice. This is advantageous when only small amounts of biopsy samples are available for analyses. Using a large amount of tumor tissue, biomarker candidates for tumor diagnosis can be investigated using multi-omics analyses [47]. Additionally, biological samples other than tumor tissues, such as blood and urine, can be obtained from the PDX models, and biomarkers can be screened to diagnose tumors using proteomic and metabolomic analyses [48, 49].

The responsiveness to treatment in the PDX models is highly relevant for therapeutic responsiveness in patients $[7,8,50]$. Therefore, PDX models can be applied to develop biomarkers that predict therapeutic responsiveness. Rather than evaluating the therapeutic effect on the patient group directly, the PDX cohort can be treated and classified into responsive and nonresponsive groups. The characteristics of two groups can be compared, which can provide biomarker candidates.
In particular, PDX models offer the advantage of maintaining patient tumor characteristics and allow easy acquisition of biological samples, which can be applied to develop biomarkers $[6,46]$. It is also possible to prospectively analyze PDX models to determine whether the biomarker is associated with the therapeutic effect; thus, PDX models can be used as a tool to validate biomarkers preclinically.

\section{Evaluation of therapeutic efficacy}

One of the largest obstacles for drug development in cancer chemotherapy is the limitation of models that precisely reflect the patient's status. Although current drug development has been mainly carried out using cell line models, various studies have reported that the drug responsiveness in the cell line models does not sufficiently reflect in human patients. Cell line models cannot retain tumor heterogeneity and components of the tumor microenvironment present in the patients' tumors [51], resulting in different treatment responsiveness. Previously used mouse models, including cell line xenograft models and GEM models of cancer-related genes, also have limitations in the validation of drug responsiveness because they do not exhibit the genetic diversity observed in cancer patients [5]. Thus, the effects seen in preclinical models may fail to be replicated in clinical trials, when these models are applied for the anti-cancer drug development process.

The PDX cohort has the advantage of being used as a model for genomic analyses while ensuring genetic diversity in cancer patients. Several previous reports have shown that drug responsiveness in PDX models is very similar to clinically applied drug responsiveness $[6,7$, 50]. Therefore, evaluation of drug effectiveness in PDX cohorts can demonstrate the diversity of drug responsiveness in real patient groups. Additionally, it is possible to study the factors that determine drug responsiveness by identifying the responsive and non-responsive subgroups and analyzing their characteristics. Therefore, the PDX model is a valuable tool to validate anticancer drug effectiveness.

\section{Drug resistance}

Analyzing the responsiveness to specific drugs in the PDX cohort demonstrates the diversity of responsiveness observed in patients and allows the classification of responsive and non-responsive groups. The characteristics of the two subgroups can be compared using multiomics analyses [11, 21,52]. Specific characteristics of the non-responders identified using this approach can be used to develop biomarkers to predict drug responsiveness and can be applied to discover new targets applicable to combination therapy [52]. Prospective 
application of these results to PDX cohorts also allows validation of biomarkers or therapeutic targets [53].

\section{Co-clinical trial}

The final validation of the current drug development process occurs through clinical trials in patients. Clinical trials include phase 1 trials that prioritize toxicity assessments, phase 2 trials that evaluate the efficacy and titration of drugs in small-scale patients, and phase 3 clinical trials that evaluate the efficacy of drugs in large-scale patients [54]. However, because this process requires much time and money, efforts are being made to implement the clinical trial process more efficiently. One such approach is a co-clinical trial that involves both a clinical trial for patients and a preclinical trial using mouse models [55]. Concomitant with the clinical trials for patients, evaluation of drug responsiveness using PDX models can be used to obtain data on drug responsiveness, thus saving time and cost. Through this process, the protocol of clinical trials can be optimized. Additionally, analyses of the mouse models allow the simultaneous study of biomarkers related to drug responsiveness $[56,57]$, thus saving many resources required in the clinical trial process and increasing efficiency. Therefore, PDX models can be used at various stages of drug development for effective development of cancer therapeutics.

\section{Future directions}

\section{A genomically defined large PDX cohort}

One of the suggested applications of PDX models is to adopt them as surrogates of matched cancer patients for drug responsiveness. By screening several chemotherapeutic drugs in PDX models, the most effective drug can be recommended prior to patient treatment. However, this approach is difficult to apply for conventional cancer treatment because the generation of PDX models is not successful in all patients and several months are required to obtain drug responsiveness data from PDX models [6]. Instead, the PDX cohorts with genomic data are a powerful tool for drug development. Because PDX models usually retain the genomic and transcriptomic characteristics of patient tumors, data from the screening of a specific drug can be further analyzed based on genomic profiles. A previous study demonstrated the feasibility of PDX clinical trials using approximately 1000 PDX models for 62 treatments and suggested several candidates for targeted therapy, biomarkers, and resistance mechanisms [52]. To utilize the PDX cohort for the drug development process, a large PDX cohort is required. Therefore, several consortium groups have tried to construct large PDX cohorts such as the EurOPDX consortium, the US National Cancer Institute repository of patient-derived models, and the Public Repository of Xenografts (Table 3) [38]. These genomically defined
PDX cohorts can be applied for all aspects of drug development processes.

\section{Organoid-based PDXs}

Patient-derived tumor organoids (PDTOs) are threedimensional cell cultures derived from cancerous cells of patients' tumor tissues [58]. PDTOs have been suggested as a preclinical model for precision oncology because they retain the genomic and histological characteristics of patients' tumors [58, 59]. Compared with PDX models, PDTOs show a higher success rate and ease-ofuse and can be applied for high-throughput screening $[58,59]$. By contrast, PDX models preserve tumor heterogeneity and tumor-stromal interactions of patients' tumors and are more relevant to study in vivo cancer biology and drug responsiveness [59]. Therefore, the integration of PDX and PDTO studies will bring more opportunities for precision oncology research. For example, PDX models can be established from PDTOs to increase the engraftment rate and PDTOs can be derived from PDX models for high-throughput drug screening. Additionally, combining drug responsiveness data from both models can increase the predictability of drug efficacy in clinical trials.

\section{PDX models for the tumor microenvironment}

Tumor tissue not only includes tumor cells but also non-malignant cells, including fibroblasts, immune cells, and endothelial cells. These surrounding cells interact with the tumor cells in various ways. The individual cells and their interactions inside the tumor tissue comprise the tumor microenvironment [60], which affects various phenotypes related to tumor biology. The tumor microenvironment has been reported to be associated with tumor aggressiveness, metastasis, and treatment responsiveness $[61,62]$. Because PDX models generally use immunodeficient mice, limitations exist in studying the functions of immune cells in the tumor microenvironment. However, the tumor microenvironment can be studied in relation to the function of other cell types. When tumor tissues are transplanted into mice, nonmalignant cells present in the tumor tissues are also transplanted together. Thus, in the case of an earlypassage PDX model, there is a possibility to study the function of human-derived non-malignant cells. Analysis of the early-passage PDX model revealed that the extracellular matrix is maintained in about half of the PDX models, and in the remaining half, the extracellular matrix is replaced by mouse-derived proteins [11]. However, endothelial cells were mostly replaced by mousederived cells in all PDX models [11]; therefore, the use of PDX models may be limited in the case of antibodies targeting human-derived blood vessels. As the passage of the PDX model progresses, the proportion of human- 


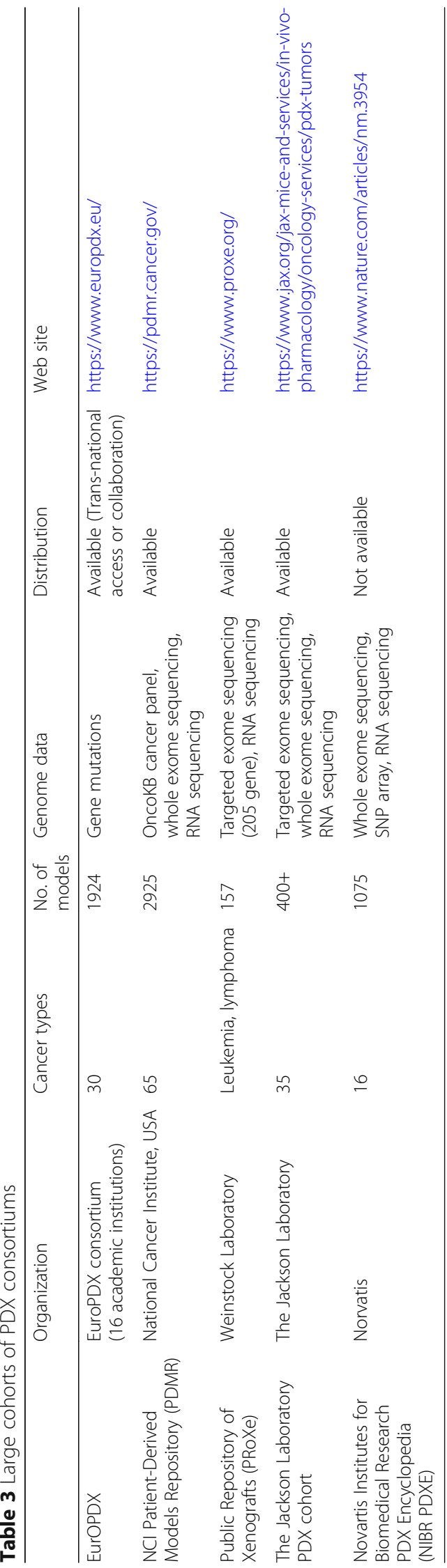


derived cells decreases and the tumor microenvironment is gradually replaced by mouse-derived cells. Thus, it is necessary to considering these changes in the tumor microenvironment, while conducting experiments.

The development of several immune checkpoint inhibitors has opened new ways to cure cancers by harnessing the patient's immunity [63]. In contrast to the success of cancer immunotherapy in clinics, the tools to investigate the preclinical effectiveness and underlying molecular mechanisms remain limited. Conventional PDX models are generated in immunodeficient mice; therefore, these models lack immune systems that resemble those of the host strains. To overcome these limitations, humanized mice, in which the immune cells are reconstituted by injecting $\mathrm{CD}_{34}{ }^{+}$human hematopoietic stem and precursor cells [64], can be used to generate PDX models (Fig. 2; Table 2). The humanized PDX models can be established in partially human leukocyte antigenmatched allogenic immune systems. Infiltration of immune cells into tumors and tumor growth inhibition were observed with anti-PD1 therapy [65]. To improve the efficacy of the reconstitution of human immune cells, several transgenic or knock-in mouse models with human cytokines, such as macrophage colony-stimulating factor (CSF), IL3, granulocyte-macrophage-CSF, and stem cell factor, have been tried, especially to develop innate immune cells $[66,67]$. The humanized PDX models are more relevant to study cancer biology, such as tumor structure, metastasis, and signaling, and can be a powerful tool to investigate cancer immunotherapy.

In the tumor microenvironment, stromal cells are highly associated with tumor aggressiveness, metastasis, and treatment responsiveness [61, 62]. Additionally, in PDX models, the components of the tumor microenvironment are steadily substituted by murine stroma as the xenografts are serially passaged [38]. To compensate for the human stromal component in PDX tumors, the strategy of co-engrafting human mesenchymal stem cells (MSCs) or cancer-associated fibroblasts with tumor tissue was investigated (Table 2) [45]. In breast cancer PDX models, implantation of human MSCs with tumors enhanced tumor growth and vascularization, preserving estrogen receptor expression [68]. However, the application of MSCs for PDX model generation needs to be carefully examined because the effect of MSCs in tumor development remains controversial [45].

\section{Circulating tumor cell (CTC)-derived xenograft models}

To establish PDX models, human tumor tissues need to be obtained by a surgical procedure or biopsy, which are very invasive methods for patients. For some types of cancers, it is almost impossible to obtain human tumor tissues. Additionally, a small fragment of tumor tissue is usually implanted for PDX generation, resulting in the loss of the intra-tumoral heterogeneity of whole human tumors. To overcome these limitations, CTC-derived xenograft models were attempted, in which the captured CTCs from patient blood samples were implanted into immunodeficient mice (Fig. 3; Table 2) [69, 70]. CTCs can be obtained from patient blood samples, which avoids the invasive procedure for patients $[69,70]$. Additionally, all parts of the tumor comprise CTCs; therefore, CTCs are a mixed population of cancer cells that retain the intra-tumoral heterogeneity of patients [69, 70]. CTCs can be harvested using several capturing methods, including physical property-dependent enrichment using size and density differences and biological property-dependent enrichment using immunoaffinity capture [69]. In size-based separation, CTCs show a larger size and stiffness than blood cells; therefore, they can be enriched using membrane filters or microfluidic devices [71]. In density-based separation, CTCs are enriched based on the difference in the relative densities between CTCs and blood cells using density-based gradient centrifugation or isopycnic density gradient centrifugation [72]. Immunoaffinity-based CTC enrichment uses antibodies against CTC-specific surface markers such as EpCAM and other stem cell or mesenchymal markers [71]. In the small cell lung cancer cohort, from which tumor tissues are rarely obtainable, CTC-derived xenograft models showed considerable similarity of genomic characteristics to patients and mirrored the patients' responsiveness to chemotherapy [73]. Additionally, CTC-derived xenografts were successfully established in several tumor types, including breast cancer, prostate cancer, gastric cancer, and melanoma [74-77].

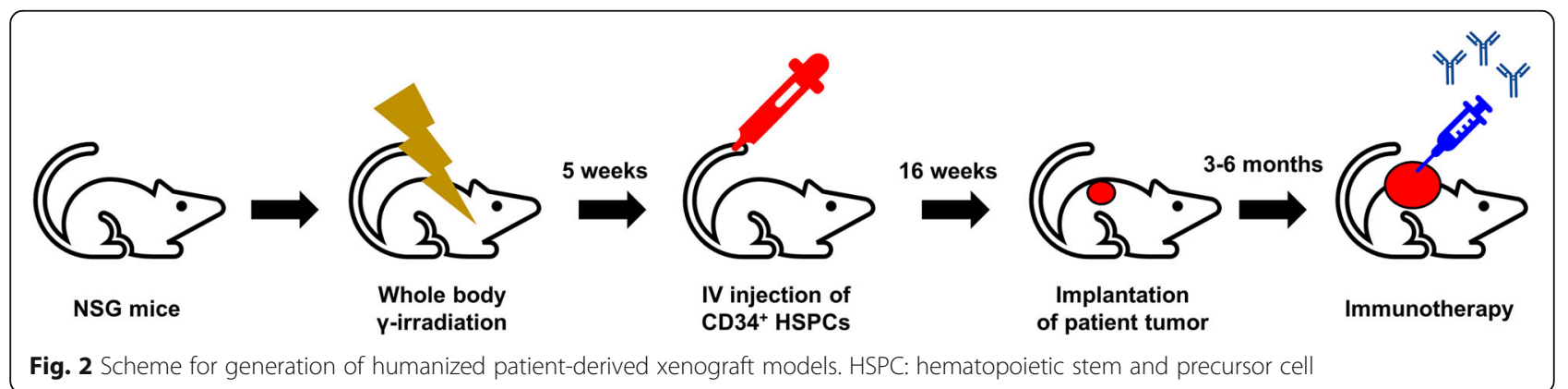




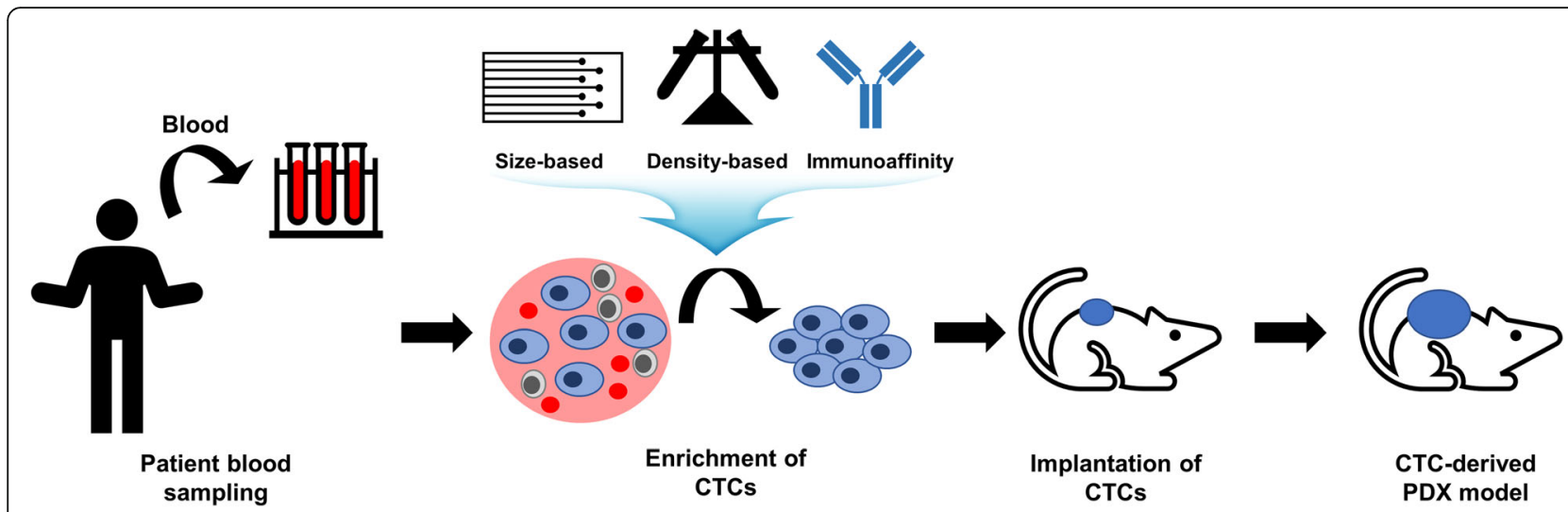

Fig. 3 Scheme for generation of circulating tumor cell (CTC)-derived patient-derived xenograft (PDX) models

\section{Modified response evaluation criteria in solid tumors (RECIST)}

In experiments using PDX models, tumor growth retardation compared with the control treatment group is usually regarded as effective. However, this evaluation does not always guarantee clinical effectiveness because, in this situation, the final tumor volume can be larger than the initial tumor volume. Therefore, quantitative metrics need to be adopted to evaluate the therapeutic effect more precisely [38]. In clinical situations, RECIST guidelines are prevalently used to assess treatment responsiveness [78]. Correspondingly, modified RECIST (mRECIST) was suggested to evaluate treatment responsiveness in PDX models [52]. mRECIST is estimated by the 'Best Response', which is defined as the minimum percent volume change for 10 days, and 'Best Average Response', which is defined as the minimum value of the average percent volume change for 10 days compared with the initial volume. Additionally, each criterion is described as follows: modified complete response (mCR), Best Response $<-95 \%$ and Best Average Response $<-40 \%$; modified partial response (mPR), Best Response < $50 \%$ and Best Average Response $<-20 \%$; modified stable disease (mSD), Best Response $<35 \%$ and Best Average Response $<30 \%$; modified progressive disease (mPD), not otherwise categorized [52]. For precise evaluation of treatment responsiveness, standardized and quantitative criteria need to be applied.

\section{Conclusions}

Precision oncology requires detailed diagnostic stratification of patients based on genomic profiling and tailored therapeutics compatible with patients' characteristics. Because PDX models are generated from patient tumor tissues, several aspects of human patient tumors including genomic and histological characteristics are readily preserved. Because of this advantage,
PDX models provide a powerful route for several steps of the drug development process in precision oncology, such as drug efficacy testing, biomarker development, drug resistance studies, and co-clinical trials. When appropriately applied by weighing the pros and cons, PDX models are very useful to advance precision oncology.

\section{Abbreviations \\ CAFs: Cancer-associated fibroblasts; CTC: Circulating tumor cell; EBV: Epstein- Barr virus; GEM: Genetically engineered mouse; HSPCs: Human hematopoietic stem and precursor cells; MSC: Mesenchymal stem cells; mCR: Modified complete response; mPD: Modified progressive disease; mPR: Modified partial response; mRECIST: Modified response evaluation criteria in solid tumors; mSD: Modified stable disease; NOD: Non-obese diabetic; NSG: NOD / scid / IL2Y-receptor null; PDX: Patient-derived xenograft; PRoXe: Public Repository of Xenografts; RECIST: Response evaluation criteria in solid tumors; scid: severe combined immuno-deficient}

\section{Acknowledgments}

Not applicable.

Author's contributions

SYC designed the study and prepared the manuscript. The author(s) read approved the final manuscript.

\section{Funding}

This work was supported by Bio \& Medical Technology Development Program of NRF, funded by the Ministry of Science \& ICT (grant No. 2018M3A9F3056902 and NRF-2019M3E5D4066900).

Availability of data and materials

The datasets generated during the current study are available.

Competing interests

The author declares no conflicts of interest.

\section{Author details}

'Department of Biomedical Sciences, Seoul National University College of Medicine, 103 Daehak-ro, Jongno-gu, Seoul 03080, South Korea. ${ }^{2}$ Cancer Research Institute, Seoul National University College of Medicine, Seoul, South Korea. ${ }^{3}$ Medical Research Center, Genomic Medicine Institute (GMI), Seoul National University, Seoul, South Korea. 
Received: 13 February 2020 Accepted: 6 May 2020 Published online: 20 May 2020

\section{References}

1. Cancer Genome Atlas Network. Comprehensive molecular characterization of human colon and rectal cancer. Nature. 2012;487(7407):330-7.

2. Cancer Genome Atlas Research Network. Comprehensive molecular characterization of gastric adenocarcinoma. Nature. 2014;513(7517):202-9.

3. Campbell JD, Alexandrov A, Kim J, Wala J, Berger AH, Pedamallu CS, Shukla SA, Guo G, Brooks AN, Murray BA, et al. Distinct patterns of somatic genome alterations in lung adenocarcinomas and squamous cell carcinomas. Nat Genet. 2016;48(6):607-16.

4. Garraway LA, Verweij J, Ballman KV. Precision oncology: an overview. J Clin Oncol. 2013;31(15):1803-5.

5. Day CP, Merlino G, Van Dyke T. Preclinical mouse cancer models: a maze of opportunities and challenges. Cell. 2015;163(1):39-53.

6. Cho SY, Kang W, Han JY, Min S, Kang J, Lee A, Kwon JY, Lee C, Park H. An integrative approach to precision Cancer medicine using patient-derived Xenografts. Mol Cells. 2016;39(2):77-86.

7. Rosfjord E, Lucas J, Li G, Gerber HP. Advances in patient-derived tumor xenografts: from target identification to predicting clinical response rates in oncology. Biochem Pharmacol. 2014;91(2):135-43.

8. Hidalgo M, Amant F, Biankin AV, Budinska E, Byrne AT, Caldas C, Clarke RB, de Jong S, Jonkers J, Maelandsmo GM, et al. Patient-derived xenograft models: an emerging platform for translational cancer research. Cancer Discov. 2014;4(9):998-1013.

9. Hernandez MC, Bergquist JR, Leiting JL, Ivanics T, Yang L, Smoot RL, Nagorney DM, Truty MJ. Patient-derived xenografts can be reliably generated from patient clinical biopsy specimens. J Gastrointest Surg. 2019; 23(4):818-24.

10. Guerrera F, Tabbo F, Bessone L, Maletta F, Gaudiano M, Ercole E, Annaratone L, Todaro M, Boita M, Filosso PL, et al. The influence of tissue ischemia time on RNA integrity and patient-derived xenografts (PDX) engraftment rate in a non-small cell lung cancer (NSCLC) biobank. PLoS One. 2016;11(1): e0145100

11. Cho SY, Sung CO, Chae J, Lee J, Na D, Kang W, Kang J, Min S, Lee A, Kwak $E$, et al. Alterations in the rho pathway contribute to Epstein-Barr virusinduced lymphomagenesis in immunosuppressed environments. Blood. 2018;131(17):1931-41.

12. Aytes A, Mollevi DG, Martinez-Iniesta M, Nadal M, Vidal A, Morales A, Salazar R, Capella G, Villanueva A. Stromal interaction molecule 2 (STIM2) is frequently overexpressed in colorectal tumors and confers a tumor cell growth suppressor phenotype. Mol Carcinogen. 2012;51(9):746-53.

13. Chen Q, Wei T, Wang J, Zhang Q, Li J, Zhang J, Ni L, Wang Y, Bai X, Liang T. Patient-derived xenograft model engraftment predicts poor prognosis after surgery in patients with pancreatic cancer. Pancreatology. 2020;20(3):485-92 [Epub ahead of print].

14. Mattie M, Christensen A, Chang MS, Yeh W, Said S, Shostak Y, Capo L, Verlinsky A, An Z, Joseph I, et al. Molecular characterization of patientderived human pancreatic tumor xenograft models for preclinical and translational development of cancer therapeutics. Neoplasia. 2013;15(10): 1138-50.

15. Lee HW, Lee Jl, Lee SJ, Cho HJ, Song HJ, Jeong DE, Seo YJ, Shin S, Joung JG, Kwon YJ, et al. Patient-derived xenografts from non-small cell lung cancer brain metastases are valuable translational platforms for the development of personalized targeted therapy. Clin Cancer Res. 2015;21(5):1172-82.

16. Dong X, Guan J, English JC, Flint J, Yee J, Evans K, Murray N, MacAulay C, Ng RT, Gout PW, et al. Patient-derived first generation xenografts of non-small cell lung cancers: promising tools for predicting drug responses for personalized chemotherapy. Clin Cancer Res. 2010;16(5):1442-51.

17. Leiting JL, Murphy SJ, Bergquist JR, Hernandez MC, Ivanics T, Abdelrahman AM, Yang L, Lynch I, Smadbeck JB, Cleary SP, et al. Biliary tract cancer patient-derived xenografts: surgeon impact on individualized medicine. JHEP Rep. 2020;2(2):100068

18. Kimple RJ, Harari PM, Torres AD, Yang RZ, Soriano BJ, Yu M, Armstrong EA, Blitzer GC, Smith MA, Lorenz LD, et al. Development and characterization of HPV-positive and HPV-negative head and neck squamous cell carcinoma tumorgrafts. Clin Cancer Res. 2013;19(4):855-64.

19. Zhao XM, Liu ZG, Yu LT, Zhang YJ, Baxter P, Voicu H, Gurusiddappa S, Luan J, Su JM, Leung HCE, et al. Global gene expression profiling confirms the molecular fidelity of primary tumor-based orthotopic xenograft mouse models of medulloblastoma. Neuro-Oncology. 2012;14(5):574-83.

20. Zhang X, Claerhout S, Prat A, Dobrolecki LE, Petrovic I, Lai Q, Landis MD, Wiechmann L, Schiff R, Giuliano M, et al. A renewable tissue resource of phenotypically stable, biologically and ethnically diverse, patient-derived human breast cancer xenograft models. Cancer Res. 2013;73(15):4885-97.

21. Li S, Shen D, Shao J, Crowder R, Liu W, Prat A, He X, Liu S, Hoog J, Lu C, et al. Endocrine-therapy-resistant ESR1 variants revealed by genomic characterization of breast-cancer-derived xenografts. Cell Rep. 2013;4(6):1116-30.

22. Choi YY, Lee JE, Kim H, Sim MH, Kim KK, Lee G, Kim HI, An JY, Hyung WJ, Kim CB, et al. Establishment and characterisation of patient-derived xenografts as paraclinical models for gastric cancer. Sci Rep. 2016;6:22172.

23. Zhu M, Li L, Lu T, Yoo H, Zhu J, Gopal P, Wang SC, Porempka MR, Rich NE, Kagan $S$ et al. Uncovering biological factors that regulate hepatocellular carcinoma growth using patient derived xenograft assays. Hepatology. 2020 Jan 3 [Epub ahead of print].

24. Sivanand S, Pena-Llopis S, Zhao H, Kucejova B, Spence P, Pavia-Jimenez A, Yamasaki T, McBride DJ, Gillen J, Wolff NC, et al. A validated tumorgraft model reveals activity of dovitinib against renal cell carcinoma. Sci Transl Med. 2012;4(137):137ra75.

25. Park B, Jeong BC, Choi YL, Kwon GY, Lim JE, Seo SI, Jeon SS, Lee HM, Choi $H Y$, Lee KS. Development and characterization of a bladder cancer xenograft model using patient-derived tumor tissue. Cancer Sci. 2013;104(5): $631-8$.

26. Nemati F, Sastre-Garau X, Laurent C, Couturier J, Mariani P, Desjardins L, Piperno-Neumann S, Lantz O, Asselain B, Plancher C, et al. Establishment and characterization of a panel of human uveal melanoma xenografts derived from primary and/or metastatic tumors. Clin Cancer Res. 2010;16(8): 2352-62.

27. Zhang X, Lewis MT. Establishment of patient-derived xenograft (PDX) models of human breast cancer. Curr Protoc Mouse Biol. 2013;3(1):21-9.

28. Garrido-Laguna I, Uson M, Rajeshkumar NV, Tan AC, de Oliveira E, Karikari C, Villaroel MC, Salomon A, Taylor G, Sharma R, et al. Tumor engraftment in nude mice and enrichment in stroma-related gene pathways predict poor survival and resistance to gemcitabine in patients with pancreatic cancer. Clin Cancer Res. 2011;17(17):5793-800.

29. Guo S, Gao S, Liu R, Shen J, Shi X, Bai S, Wang H, Zheng K, Shao Z, Liang C, et al. Oncological and genetic factors impacting PDX model construction with NSG mice in pancreatic cancer. FASEB J. 2019;33(1):873-84.

30. Moon HG, Oh K, Lee J, Lee M, Kim JY, Yoo TK, Seo MW, Park AK, Ryu HS, Jung EJ, et al. Prognostic and functional importance of the engraftmentassociated genes in the patient-derived xenograft models of triple-negative breast cancers. Breast Cancer Res Treat. 2015;154(1):13-22.

31. Massimo M, Giulia B, Roberto C, Cristina B, Mattia B, Alessandra F, Giorgia L, Patrizia G, Carlotta G, Giuseppe P, et al. Establishment of patient derived xenografts as functional testing of lung cancer aggressiveness. Sci Rep. 2017;7(1):6689.

32. Segre JA, Nemhauser JL, Taylor BA, Nadeau JH, Lander ES. Positional cloning of the nude locus - genetic, physical, and transcription maps of the region and mutations in the mouse and rat. Genomics. 1995;28(3):549-59.

33. Jhappan C, Morse HC, Fleischmann RD, Gottesman MM, Merlino G. DNAPKcs: a T-cell tumour suppressor encoded at the mouse scid locus. Nat Genet. 1997:17(4):483-6.

34. Larochelle A, Vormoor J, Hanenberg H, Wang JCY, Bhatia M, Lapidot T, Moritz T, Murdoch B, Xiang LX, Kato I, et al. Identification of primitive human hematopoietic cells capable of repopulating NOD/SCID mouse bone marrow: implications for gene therapy. Nat Med. 1996;2(12):1329-37.

35. Shultz LD, Ishikawa F, Greiner DL. Humanized mice in translational biomedical research. Nat Rev Immunol. 2007;7(2):118-30.

36. Zhang LH, Liu YQ, Wang XH, Tang ZY, Li SX, Hu Y, Zong XL, Wu XJ, Bu ZD, Wu AW, et al. The extent of inflammatory infiltration in primary cancer tissues is associated with lymphomagenesis in immunodeficient mice. Sci Rep. 2015;5:9447.

37. Hoffman RM. Patient-derived orthotopic xenografts: better mimic of metastasis than subcutaneous xenografts. Nat Rev Cancer. 2015;15(8):451-2.

38. Byrne AT, Alferez DG, Amant F, Annibali D, Arribas J, Biankin AV, Bruna A, Budinska E, Caldas C, Chang DK, et al. Interrogating open issues in cancer precision medicine with patient-derived xenografts. Nat Rev Cancer. 2017; 17(4):254-68.

39. Dobrolecki LE, Airhart SD, Alferez DG, Aparicio S, Behbod F, Bentires-Alj M, Brisken C, Bult CJ, Cai SR, Clarke RB, et al. Patient-derived xenograft (PDX) 
models in basic and translational breast cancer research. Cancer Metast Rev. 2016;35(4):547-73.

40. Wang YZ, Wang JX, Xue H, Lin D, Dong X, Gout PW, Gao X, Pang J. Subrenal capsule grafting technology in human cancer modeling and translational cancer research. Differentiation. 2016;91(4-5):15-9.

41. Rea D, del Vecchio V, Palma G, Barbieri A, Falco M, Luciano A, De Biase D, Perdona S, Facchini G, Arra C. Mouse models in prostate cancer translational research: from xenograft to PDX. Biomed Res Int. 2016;2016:9750795.

42. Scott CL, Becker MA, Haluska P, Samimi G. Patient-derived xenograft models to improve targeted therapy in epithelial ovarian cancer treatment. Front Oncol. 2013;3:295.

43. Melo FDE, Vermeulen L, Fessler E, Medema JP. Cancer heterogeneity-a multifaceted view. EMBO Rep. 2013;14(8):686-95.

44. Pribluda A, de la Cruz CC, Jackson EL. Intratumoral heterogeneity: from diversity comes resistance. Clin Cancer Res. 2015;21(13):2916-23.

45. Cassidy JW, Caldas C, Bruna A. Maintaining tumor heterogeneity in patientderived tumor xenografts. Cancer Res. 2015;75(15):2963-8.

46. Jung J, Seol HS, Chang S. The generation and application of patient-derived xenograft model for cancer research. Cancer Res Treat. 2018;50(1):1-10.

47. Li L, Wei YH, To C, Zhu CQ, Tong JF, Pham NA, Taylor P, Ignatchenko V, Ignatchenko A, Zhang W, et al. Integrated omic analysis of lung cancer reveals metabolism proteome signatures with prognostic impact. Nat Commun. 2014:5:5469.

48. Liu YT, Wang YZ, Cao ZX, Gao YH. Changes in the urinary proteome in a patient-derived xenograft (PDX) nude mouse model of colorectal tumor. Sci Rep. 2019;9(1):4975.

49. Thangavel $H$, De Angelis C, Vasaikar S, Bhat $R$, Jolly MK, Nagi C, Creighton CJ, Chen FJ, Dobrolecki LE, George JT, et al. A CTC-cluster-specific signature derived from OMICS analysis of patient-derived xenograft tumors predicts outcomes in basal-like breast cancer. J Clin Med. 2019;8(11):1772.

50. Hidalgo M, Bruckheimer E, Rajeshkumar NV, Garrido-Laguna I, De Oliveira E, Rubio-Viqueira B, Strawn S, Wick MJ, Martell J, Sidransky D. A pilot clinical study of treatment guided by personalized tumorgrafts in patients with advanced cancer. Mol Cancer Ther. 2011;10(8):1311-6.

51. Wilding $J$, Bodmer WF. Cancer cell lines for drug discovery and development. Cancer Res. 2014;74(9):2377-84.

52. Gao H, Korn JM, Ferretti S, Monahan JE, Wang YZ, Singh M, Zhang C, Schnell C, Yang GZ, Zhang Y, et al. High-throughput screening using patient-derived tumor xenografts to predict clinical trial drug response. Nat Med. 2015;21(11):1318-25.

53. Bonanno L, De Paoli A, Zulato E, Esposito G, Calabrese F, Favaretto A, Santo A, Conte AD, Chilosi M, Oniga F, et al. LKB1 expression correlates with increased survival in patients with advanced non-small cell lung cancer treated with chemotherapy and bevacizumab. Clin Cancer Res. 2017;23(13): 3316-24.

54. Umscheid CA, Margolis DJ, Grossman CE. Key concepts of clinical trials: a narrative review. Postgrad Med. 2011;123(5):194-204.

55. Clohessy JG, Pandolfi PP. Mouse hospital and co-clinical trial project-from bench to bedside. Nat Rev Clin Oncol. 2015;12(8):498.

56. Kim HR, Kang HN, Shim HS, Kim EY, Kim J, Kim DJ, Lee JG, Lee CY, Hong $\mathrm{MH}$, Kim SM, et al. Co-clinical trials demonstrate predictive biomarkers for dovitinib, an FGFR inhibitor, in lung squamous cell carcinoma. Ann Oncol. 2017;28(6):1250-9.

57. Varkaris A, Corn PG, Parikh NU, Efstathiou E, Song JH, Lee YC, Aparicio A, Hoang AG, Gaur S, Thorpe L, et al. Integrating murine and clinical trials with cabozantinib to understand roles of MET and VEGFR2 as targets for growth inhibition of prostate cancer. Clin Cancer Res. 2016;22(1):107-21.

58. Aboulkheyr Es $\mathrm{H}$, Montazeri L, Aref AR, Vosough M, Baharvand $H$. Personalized cancer medicine: An organoid approach. Trends Biotechnol. 2018;36(4):358-71.

59. Bleijs $M$, van de Wetering $M$, Clevers $H$, Drost J. Xenograft and organoid model systems in cancer research. EMBO J. 2019;38(15):e101654.

60. Whiteside $\mathrm{TL}$. The tumor microenvironment and its role in promoting tumor growth. Oncogene. 2008;27(45):5904-12.

61. Tan Q, Saggar JK, Yu M, Wang M, Tannock IF. Mechanisms of drug resistance related to the microenvironment of solid tumors and possible strategies to inhibit them. Cancer J. 2015;21(4):254-62.

62. Tredan O, Galmarini CM, Patel K, Tannock IF. Drug resistance and the solid tumor microenvironment. J Natl Cancer Inst. 2007;99(19):1441-54.

63. Pardoll DM. The blockade of immune checkpoints in cancer immunotherapy. Nat Rev Cancer. 2012;12(4):252-64.
64. Morton JJ, Bird G, Refaeli Y, Jimeno A. Humanized mouse xenograft models: narrowing the tumor-microenvironment gap. Cancer Res. 2016;76(21):61538.

65. Wang MA, Yao LC, Cheng MS, Cai DY, Martinek J, Pan CX, Shi W, Ma AH, White RWD, Airhart $\mathrm{S}$, et al. Humanized mice in studying efficacy and mechanisms of PD-1-targeted cancer immunotherapy. FASEB J. 2018;32(3): 1537-49.

66. Rongvaux A, Willinger T, Martinek J, Strowig T, Gearty SV, Teichmann LL, Saito Y, Marches F, Halene S, Palucka AK, et al. Development and function of human innate immune cells in a humanized mouse model. Nat Biotechnol. 2014;32(4):364-72.

67. Wunderlich M, Chou FS, Link KA, Mizukawa B, Perry RL, Carroll M, Mulloy JC. AML xenograft efficiency is significantly improved in NOD/SCID-IL2RG mice constitutively expressing human SCF, GM-CSF and IL-3. Leukemia. 2010; 24(10):1785-8

68. DeRose YS, Wang GY, Lin YC, Bernard PS, Buys SS, Ebbert MTW, Factor R, Matsen C, Milash BA, Nelson E, et al. Tumor grafts derived from women with breast cancer authentically reflect tumor pathology, growth, metastasis and disease outcomes. Nat Med. 2011;17(11):1514-20.

69. Tellez-Gabriel M, Cochonneau D, Cade M, Jubellin C, Heymann MF, Heymann D. Circulating tumor cell-derived pre-clinical models for personalized medicine. Cancers. 2018;11(1):19.

70. Praharaj PP, Bhutia SK, Nagrath S, Bitting RL, Deep G. Circulating tumor cellderived organoids: current challenges and promises in medical research and precision medicine. Biochim Biophys Acta Rev Cancer. 2018;1869(2): 117-27.

71. Banko P, Lee SY, Nagygyorgy V, Zrinyi M, Chae CH, Cho DH, Telekes A. Technologies for circulating tumor cell separation from whole blood. J Hematol Oncol. 2019;12(1):48.

72. Ferreira MM, Romani VC, Jeffrey SS. Circulating tumor cell technologies. Mol Oncol. 2016;10(3):374-94.

73. Hodgkinson CL, Morrow CJ, Li Y, Metcalf RL, Rothwell DG, Trapani F, Polanski R, Burt DJ, Simpson KL, Morris K, et al. Tumorigenicity and genetic profiling of circulating tumor cells in small-cell lung cancer. Nat Med. 2014; 20(8):897-903.

74. Baccelli I, Schneeweiss A, Riethdorf S, Stenzinger A, Schillert A, Vogel V, Klein C, Saini M, Bauerle T, Wallwiener M, et al. Identification of a population of blood circulating tumor cells from breast cancer patients that initiates metastasis in a xenograft assay. Nat Biotechnol. 2013;31(6):539-44.

75. Williams ES, Rodriguez-Bravo V, Chippada-Venkata U, De la Iglesia-Vicente J, Gong YX, Galsky M, Oh W, Cordon-Cardo C, Domingo-Domenech J. Generation of prostate cancer patient derived xenograft models from circulating tumor cells. J Vis Exp. 2015;105:53182.

76. Toyoshima K, Hayashi A, Kashiwagi M, Hayashi N, Iwatsuki M, Ishimoto T, Baba Y, Baba H, Ohta Y. Analysis of circulating tumor cells derived from advanced gastric cancer. Int J Cancer. 2015;137(4):991-8.

77. Girotti MR, Gremel G, Lee R, Galvani E, Rothwell D, Viros A, Mandal AK, Lim $\mathrm{KH}$, Saturno G, Furney SJ, et al. Application of sequencing, liquid biopsies, and patient-derived xenografts for personalized medicine in melanoma. Cancer Discov. 2016;6(3):286-99.

78. Therasse P, Arbuck SG, Eisenhauer EA, Wanders J, Kaplan RS, Rubinstein L, Verweij J, Van Glabbeke M, van Oosterom AT, Christian MC, et al. New guidelines to evaluate the response to treatment in solid tumors. J Natl Cancer Inst. 2000;92(3):205-16.

\section{Publisher's Note}

Springer Nature remains neutral with regard to jurisdictional claims in published maps and institutional affiliations. 